\title{
Reanalysis of the Causes of Reverse News*
}

\author{
Yaping Shen \\ Sichuan University \\ Chengdu, China
}

\begin{abstract}
The frequent occurrence of reverse news is a significant feature of the era of network communication. In this paper, the connotation and extension of the reverse news are further clarified, and the root cause of the frequent reverse news is analyzed in the framework of the news sociology. In this paper, it is considered that the fundamental change in spread ecology caused by communication and the power game of the official and the folk public opinion field are the important reasons for the frequent occurrence of the reverse news.
\end{abstract}

\section{Keywords-reverse news; cause; dialogue; game}

\section{INTRODUCTION}

The reverse news in the network communication era has become a more and more frequent social phenomenon, and the research on the reverse news has also become a hot issue in the study of journalism. The substance of the reversal in the reverse news is the reversal of public opinion or the reversal of lyric, and the reverse news is a dynamic evolution of the fact or the point of view. From the point of view of the sociology of news, the reverse news is essentially a multiplereport of the news fact or the social action to correct and rectify the news. The frequent occurrence of the reverse news, on the one hand, is the revolutionary change of the ecological environment due to the information brought by the network, on the other hand, the power game between the official public opinion field and the civil public opinion field in the public opinion field is reflected. The author thinks that the existence of the reverse news is, at present, it does more harm than good, and its negative influence on the society can not be ignored.

\section{REVERSE NEWS: A CONCEPT THAT NEEDS TO BE CLEAR}

The literal interpretation of the word "reversal" in modern Chinese means "turning in the opposite direction". News reversal, reverse news, "news reversal drama", reversal of public opinion, reversal of public opinion, false news, these words have become the focus of news communication academic research in recent years. However, there seems to be no authoritative definition of the connotation and extension of these concepts. Through literature carding and review, the author tends to agree with Professor Wang Junchao's understanding of news reversal put forward in the

*Funds: Special fund team project of basic scientific research business expenses for central universities (31920190211); Gansu Province "13th Five-Year Plan" Education Planning Project (GS [2018] GHBBK106). "reversal" of News $(2017.5)^{1}$. He believes that the so-called "news reversal" refers to the news facts or views published by the media in the process of dissemination, which is very different from the original news due to public questioning and correction of facts, a dynamic process in which news facts or opinions turn in the opposite direction.

With this concept, it can be further thought about what is reversed in the reversal of news? Is it news? Is the information? Is it still public opinion? Or lyric? Researchers are inconsistent. But at least this concept makes it clear that reverse news itself is a dynamic evolution of facts or opinions. People in the news industry, such as Jiang Hanchao, tend to think that the concept of reverse news is not very accurate. In journalism, there is no reversal of news. "Reverse news" should be called "public opinion reversal event." The so-called "reverse news" is only a new phenomenon with the rise of the network media in recent years, that is, the media began to report the voices of one side of the news events, and every once in a while reported the other side of the completely different statements and explanations, leading to the reversal of public opinion. ${ }^{2}$

Although this understanding has reasonable place, but from the news industry' s history, reverse news is not the unique phenomenon of this era, nor is it accompanied by the rise of network media to appear a new phenomenon, only in today' $\mathrm{s}$ network information dissemination environment, reverse news appears more frequently. As early as 1843, Marx put forward the "organic movement of newspapers and periodicals ", which developed into a kind of process theory about newspaper reporting news. According to the characteristics of newspaper reports, Marx demonstrated the whole process of reporting a specific event, which is manifested in the organic movement of the whole newspaper. Each report may seem one-sided and biased because of the different emphasis on the side, but as long as the organic movement of the newspaper is running normally, the truth of the incident will gradually be clearly displayed.

As a result, the basic understanding and judgment of the reverse news can be concluded: it is not a new thing to reverse the news, but it is a kind of social phenomenon to be emphasized in the times of social media. The reverse news is, in its essence, a number of reports of news fact or the social action to correct and rectify the news. The knowing and

\footnotetext{
Wang Junchao, Liu Moxiao. On the Reversal of News [J]. Press front, 2017 (05)

Jiang Hanchao, the Value of "Reversing News" and Traditional Media People [J]. Chinese journalist,2016 (3)
} 
understanding of the reverse news should be placed in the framework of the sociology of information. The reason why the reversal of news is frequent in today's network communication environment must have its underlying reasons.

\section{ANALYSIS OF THE CAUSES OF REVERSE NEWS: DIALOGUE AND GAME}

There are many reasons why reverse news has become a normal phenomenon from a "fresh" phenomenon in the traditional media era to today's era of network communication. According to the previous research results, the researchers either push the reasons to the media, such as the lack of media responsibility, or attribute the reasons to the specific level of news business operations, for example, they think that in the process of the production and dissemination of reverse news, non-news professional producers play an important role, and their media literacy needs to be improved. There is no denying that these are the causes of reverse news, but not the root cause of deep-seated news. The root cause of the frequent emergence of reverse news in this era needs to be explored from the overall characteristics of this era. To put it simply, on the one hand, this is a phenomenon inevitably caused by the ecological characteristics of network information dissemination; on the other hand, reverse news seems to be the reversal of public opinion caused by the flow of news information, which is actually a result of all kinds of power games in the field of public opinion.

\section{A. The Ecological Change of Network Information Dissemination Has Promoted the Emergence of Reverse News}

What kind of communication environment is it today? From the traditional media to the new media, what changes have taken place in the information dissemination environment? According to Roger Fydler in the Change of Media Form: Understanding New Media, the evolution of media form is usually caused by perceptual needs, competition and political pressure, as well as the complex interaction between social and technological innovations. ${ }^{3}$ So how have the factors of these dimensions changed today?

First, today, people's information demand is not the original state of passive wait information as the audience of the traditional media age, and has evolved into a diverse information demand. In the era of network communication, some people say that the "audience" is outdated, and the concept of a more neutral user should be used, in a social network of large numbers of netizens, each of which is a node, in the state of fragmentation, they proactively seek the information they want.

Second, today, the competition pressure of the media industry is not comparable; at the same time, the competitive situation is multi-level, and there are competitions in both the

Written by Roger Fydler, translated by Ming Anxiang. Change of Media form: Understanding New Media [M]. Beijing: Huaxia Publishing House. 2000 Page 19. information product market and the cultural market, the ideological market and the opinion market. Nowadays, competition between traditional media, between traditional and new media, between new media, between traditional media and converged media is becoming increasingly fierce. However, the era of a single big one is gone forever, and the current era, any media organization or individual has been unable to realize the monopoly release of the information, and at the same time, it is not possible to make a sense of the monopoly of certain news information. Thus, when news information is present, the recipient of the information is likely to be trapped in the interpretation of the vortex.

Finally, with the change of technology, the whole social form is also changing. With the rapid development of media technology, all kinds of new technologies, such as big data, cloud computing, Internet of things, artificial intelligence and so on, have become familiar terms to the general public. In such a technological environment, ordinary people have been redefined in cyberspace, and at the same time, it also reflects the huge energy that has not been brought into play in any social form in the past. To describe it mildly, Castell's Rise of Network Society can be used as a metaphor. In the form of today's network society, people's time, energy, consumption and other aspects have been fragmented; cyberspace has given users a more relaxed expression space. Therefore, people's self-consciousness begins to awaken, and a self-oriented society is coming. The choice, processing, expression and output of self-information and opinions have reached a state that the society did not have in the past. Users have the opportunity and willingness to participate in social and public affairs, in terms of social form, a civil society is coming. As an important part of civil society - cyberspace, the re-empowerment of the Internet by netizens may prompt the society to move toward a more rational state.

In short, in the era of network communication, decentralization, fragmentation and re-empowerment have become a reality. In the fundamental change of this kind of communication environment, it is inevitable that the role and function of the Internet users in the information transmission are amplified, and in the past, The general people has little access to the process of information production, but today, to a great extent, the people can be involved and can actively engage in the production and dissemination of information, that is, the time of the citizen's news has come. In this context, the emergence of reverse news seems to become an inevitable phenomenon. The characteristic of reverse news is that there may be a deviation in the specific space-time background of the media report, and this deviation may be accompanied by the emergence of new information or the reversal of netizens to make the information more comprehensive and complete. Therefore, we can not arbitrarily think that new and new medias, such as Weibo, are the distribution center of rumors. On the contrary, in many cases, it is often because netizens play an "unorganized organizational force" that the truth of things can be restored. In other words, the original news production process has been deconstructed, in the traditional media era, even after the news text has been produced, even if the audience will have feedback, but limited to technical factors, this kind of 
feedback is also minimal. In the new media era, the barriers to technology have been broken, and netizens can quickly make responses and feedback to news information, that is to say, today, the production of news texts has produced more accompanying texts. People usually interpret the meaning by these accompanying texts. Today, the more important word is "consultative dialogue". As Professor Wang Tianding put it, "News communication has opened up the mode of dialogue. Unlike the traditional mass media era, the publication of a work is no longer the end of a communication behavior, but has just begun. ${ }^{4}$ The author understands that the news communication here refers to the era of network communication. As ordinary netizens, they have been given the opportunity and possibility of dialogue with the media; in this case, the emergence of reverse news is not surprising.

\section{B. The Formation, Expansion and Evolution of Network Public Opinion Have Given Birth to Reverse News}

Professor Liu Jianming pointed out in the Introduction to Public Opinion that the emergence of modern newspapers, especially the popularization of network medium, has changed the structure of social groups and changed the process of formation, expansion and evolution of public opinion. The opportunity for public opinion to move toward rationality has increased. ${ }^{5}$

The public opinion field contains a number of mutual stimulation factors. It is a specific time-space environment for many people to form common opinions, which is a function of the interaction between the public and the environment, including the experience of many people, the real needs and the echo of each other. ${ }^{6}$ The macro-meaning of the public opinion field means the public domain of the society. Today's cyberspace can be seen as a public domain. The main factors that make up the public opinion field are the density and the frequency of communication between the people in the same space. Public opinion is generated in a specific environment, starting from a specific space. This micro-environment is called a public opinion field. The greater the density of people's build-up, the more is the conditions for the exchange of views.

Reverse news mostly ferment and develop in ups and downs in cyberspace; as mentioned above, the result and embodiment of the reversal of news is still the reversal of public opinion. Internet public opinion is formed in the Internet space, the consensus of netizens on public issues, because the virtualization and globalization of the main body of public opinion has greatly improved the ability of human communication and integration of views, and set up a platform for the general public to participate in public opinion. With multi-dimensional, omni-directional, real-time

\footnotetext{
Wang Tianding. In the Era of Dialogue, Power Game and Reversal News [J]. Young journalist, 2016 (7)

5 Liu Jianming, Ji Zhonghui, Wang Lili. Introduction to Public Opinion. [M] Beijing: Communication University of China Press. 2009. Page 153

Liu Jianming, Ji Zhonghui, Wang Lili. Introduction to Public Opinion. [M] Beijing: Communication University of China Press. 2009. Page 50
}

interactive communication structure, the network has created a new, equal, no-power and central public opinion field.

Reverse news is a complex social phenomenon, which embodies the result of power game between different subjects in the field of network public opinion. The first systematic theoretical analysis of the two public opinion fields should be Professor Tong Bing of Fudan University. In the Analysis of the Similarities and Differences of the Official and Folk Public Opinion Field, he first clarified the concept of the public opinion field, and then distinguished the similarities and differences between the official public opinion field and the folk public opinion field. ${ }^{7}$

This paper holds that the emergence of reverse news is, to some extent, the result of the game of power of these two kinds of public opinion. With the deepening of social transformation and the popularization of emerging media represented by the Internet, China has formed two new patterns of public opinion, namely, the official public opinion field and the anecdotal public opinion field, which restrict and promote each other. The main composition of the official public opinion field is the party committees and the governments at all levels, through newspapers, radio, television and other traditional media or government Weibo and other new media, according to the intention of the ruling party to issue authoritative information, interpretation of public policies, The other is the "folk public opinion field" in which netizens and the public express their views on public events and social affairs through the Internet, mobile phone and so on other emerging media.

The game between official public opinion field and folk public opinion field does not exist from time to time, but will appear only in some cases, and reverse news is a direct embodiment of this power game, or reverse news leads to the opposition between the two kinds of public opinion field. In most reverse news, it is usually seen that the news begins because it involves some of the most immediate concerns of the people, such as education, health care and other social issues, and this kind of news report is mixed with negative social emotion at the beginning, social news is the most prone to reversal of the kind of news. In the process of news reversal, the situation that often occurs is that the public opinion is the first, the official public opinion lags behind, the official public opinion is often doing the work of refuting rumors or supplementary explanation, and even the public opinion field forces the official public opinion field to respond. As far as the official is concerned, the news reversal seems to have become the "crisis public relations" over and over again. This kind of binary opposition is bound to bring about the opposition of social structure. As far as the official media is concerned, it is a repeated trampling of the credibility of the media. As far as the government, it is also pushed into the "Tacitus trap", which makes it difficult to extricate itself.

In addition, the main body of production and communication of inverted news is socialized. Apart from

Xie Wenshuai. A Summary of the Theory of "Official Public Opinion Field" and its Theoretical Discussion [J]. Audio-visual 2013(6) 
By summarizing the existing research results, this paper puts forward that reverse news is the inevitable result of the interaction of multiple agents in the new network communication environment. The analysis of the causes of the reversal of news should be explored from the overall change of the communication environment and the game of the main body of public opinion.

\section{REVERSE NEWS: A KIND OF SOCIAL EXISTENCE THAT NEEDS TO BE TREATED RATIONALLY}

Reverse news has become a common social phenomenon today. As mentioned above, on the one hand, the emergence of reverse news is the inevitable result caused by the ecological change of network information dissemination, at the same time; reverse news also reflects the result of the power game of different subjects in the field of public opinion. How can the consequences of this game be viewed rationally? The consequence of binary antagonistic game must be the decline of media credibility and government credibility, and it is also a kind of social chaos in the era of citizen news, and its influence should be more harmful than good today.

On the one hand, although the network public opinion environment is conducive to the production of rational public opinion, the different views of netizens are also conducive to the formation of a "free market of opinions." From this point of view, it is not necessary to regard reverse news as fierce floods and savage beasts or meaningless existence. Due to the development of network communication, the emergence of reverse news should be a symbol of social progress and civilization evolution.

But on the other hand, in the context of post-truth, the role of reverse news in leading the audience to the truth, and the hindrance is greater than the driving force. What reverse news provides to the public is a kind of broken truth, it is a kind of fragmented information dissemination activity, sometimes even in order to obtain the timeliness of news information and ignore the authenticity of news information. Even in the subsequent reversal, it seems that people get a certain amount of news truth, but this kind of news truth is still a certain distance from people's contact with the truth. News truth should be a kind of systematic truth, whole truth and process truth. Just as Marx mentioned "the organic movement of newspapers and periodicals", the truth of news is a dynamic process. In the era of fragmentation communication, this truth has been dispelled to a large extent. As the recipient of news, the reversal of news brings people a feeling that they are often deceived, and the media and the government are also suffering from it. There seems to be no real winner in such a society.

\section{CONCLUSION}

As far as the current research on reverse news is concerned, most of the studies are still at the level of the matter or case discussion, and there are obvious deficiencies in the analysis of the causes of reverse news. This paper holds that reverse news should be regarded as a kind of social action or social phenomenon, and the study of reverse news should be analyzed from a more profound social level.

\section{REFERENCES}

[1] Wang Junchao, Liu Moxiao. On the reversal of News [J]. Press front, 2017 (05). (in Chinese)

[2] Jiang Hanchao,the Value of "Reversing News" and Traditional Media People [J]. Chinese journalist,2016 (3). (in Chinese)

[3] Written by Roger Fydler, translated by Ming Anxiang. Change of Media form: understanding New Media [M]. Beijing: Huaxia Publishing House. 2000. (in Chinese)

[4] Wang Tianding. In the era of dialogue, power game and reversal news [J]. Young journalist, 2016 (7).

[5] Liu Jianming, Ji Zhonghui, Wang Lili. Introduction to public opinion. [M] Beijing: Communication University Of China Press. 2009. (in Chinese)

[6] Liu Jianming, Ji Zhonghui, Wang Lili. Introduction to public opinion. [M] Beijing: Communication University Of China Press. 2009. (in Chinese)

[7] Xie Wenshuai. A Summary of the Theory of "Official Public Opinion Field" and its Theoretical Discussion [J]. Audio-visual 2013(6). (in Chinese)

[8] [US] Michael Schuldsen. Sociology of Journalism. [M] Beijing: Huaxia Publishing House. 2010. 